\title{
Final Report: The Development of an Improved Cloud Microphysical Product for Model and Remote Sensing Evaluation using RACORO Observations
}

Greg M. McFarquhar, University of Illinois, Sept. 2012

We proposed to analyze data collected during the Routine Aerial Facilities (AAF) Clouds with Low Optical Water Depths (CLOWD) Optical Radiative Observations (RACORO) in order to develop an integrated product of cloud microphysical properties (number concentration of drops in different size bins, total liquid drop concentration integrated over all bin sizes, liquid water content LWC, extinction of liquid clouds, effective radius of water drops, and radar reflectivity factor) that could be used to evaluate large-eddy simulations (LES), general circulation models (GCMs) and ground-based remote sensing retrievals, and to develop cloud parameterizations with the end goal of improving the modeling of cloud processes and properties and their impact on atmospheric radiation. We have completed the development of this microphysical database and have submitted it to ARM for consideration of its inclusion on the ARM database as a PI product.

In collaboration with Dr. Haf Jonsson, we investigated the differences in the size distributions measured by the Cloud and Aerosol Spectrometer (CAS) and the Forward Scattering Probe (FSSP), between the one dimensional cloud imaging probe (1DC) and the twodimensional cloud imaging probe (2DC), and between the bulk LWCs measured by the Gerber probe against those derived from the size resolved probes. We considered these differences when selecting the probes to include in the PI product.

The CAS and FSSP both measured the smallest cloud drops, with the CAS measuring 0.4 $<D<50$ microns. Initially (through 4 March), the FSSP measured from $2<D<45$ microns. Although the FSSP particle sizing seemed fine when operating in this mode, the particle concentrations were too low. From 15 March, this issue was resolved by operating the FSSP in Range 1, which reduced the maximum drop size bin from 45 to 30 microns and increased the bin resolutions slightly. FSSP data are available from 15 March onwards. In addition, because of the potential for measurement drift that was noted, the FSSP concentrations and LWC in the original data release for most days (except March 20 and April 28) had to be multiplied by 1.71.

When determining cloud properties, only the contributions of droplets with $D>2$ microns from the CAS were considered to avoid the impact of aerosols in the distribution. To compare the performance of the CAS and FSSP, the LWC derived from the size distributions from droplets with $\mathrm{D}>2$ microns were compared against the Gerber LWC for all points with Gerber LWC > .01 $\mathrm{g} \mathrm{m}^{-3}$. We found that the CAS LWCs were generally about $25 \%$ larger than the Gerber LWCs and that the FSSP LWCs were about $15 \%$ smaller. There was some scatter in the relations for different days, with the FSSP/CAS LWCs well correlated with those from the Gerber probe for the most part. There was no appreciable difference as to which probe correlated better with the Gerber LWC. Only the CAS measured the number distribution function for D > 
30 microns; however, we showed that there was little LWC in sizes above 30 micrometers so the differing ranges of the FSSP and CAS did not explain the difference in LWC. Thus, based on the LWC comparison, we could not identify whether the FSSP or CAS should be used to characterize the small drops.

When comparing the CAS and FSSP total number concentrations in their common size range, there was found to be good agreement after 15 March when the operating range of the FSSP was changed. When deriving the integrated cloud product, we decided to use the CAS to describe the size distributions because its calibration was steadier throughout the mission than that of the FSSP which had a tendency to drift as its prism seemed vulnerable to collecting drops that somehow made their way to it. The FSSP required frequent disassembly, cleaning, and reassembly, and really a recalibration after each flight. There was a thought that the CAS could have been prone to errors on account of shatter in presence of large drops. However, this was shown not to be a problem because the relationship between the FSSP and CAS number concentrations did not change depending upon whether larger drops were measured by the 1DCIP during RACORO.

The size distributions from the 1DCIP and 2DCIP were compared in order to determine how to represent the concentrations of droplets with $\mathrm{D}>50$ microns. These comparisons yielded some differences in the size distributions of the larger drops. Analysis of images recorded by the 2DCIP suggests that some of the extra particles recorded by the 2DCIP not detected by the 1DCIP were indeed artifacts. Thus, we are currently using the 1DCIP to characterize the population of the droplets larger than those measured by the CAS. At this time, a detailed comparison of the size distributions measured by the 1DCIP and 2DS has not been conducted. Careful inspection of the 2DS images also needs to be performed to assess the presence of any shattered particles; this work still needs to be performed.

In addition to the development of the PI product of cloud properties, we also performed research, the results of which have been presented at the Fall AGU meeting, the ASR meeting, and the International Conference on Clouds and Precipitation. We examined the influence of the classical second aerosol indirect effect on the RACORO data. The second indirect effect occurs when increases in aerosol concentration lead to reductions in cloud droplet sizes, affecting the precipitation efficiency, and consequently leading to increases in LWC and cloud lifetime. Even though numerous studies have provided evidence of this effect in stratus and stratocumulus, an opposite effect may occur in shallow cumulus where decreases in LWC have been observed with increases in aerosol.

Of the 260 flight hours during RACORO, 85 were classified as shallow cumuli conditions. Daily averaged sub-cloud aerosol concentrations in the accumulation mode $(0.1$ microns $<\mathrm{D}<2.2$ microns) measured by Passive Cavity Aerosol Spectrometer Probe (PCASP), $\mathrm{N}_{\text {PCASP, }}$, varied from 70 to $1300 \mathrm{~cm}^{-3}$ for the 19 shallow cumuli flights, with a median value of $740 \mathrm{~cm}^{-3}$. Sub-cloud aerosol concentrations in the Aitken mode (D $>10 \mathrm{~nm}$ ) measured by a 
Condensation Particle Counter varied from 800 to $9500 \mathrm{~cm}^{-3}$ with a median value of $2030 \mathrm{~cm}^{-3}$. Using 1-s averaged cloud data from the FSSP, 2337 penetrations into cumuli were identified. Most of the cumuli occurred at heights below $2500 \mathrm{~m}$ and their median width was on the order of $200 \mathrm{~m}$. The average and maximum LWC, effective radius $\left(\mathrm{r}_{\mathrm{e}}\right)$, number concentration and vertical velocity were computed for the 2337 shallow cumuli. The maximum vertical velocity in cloud reached $15 \mathrm{~m} \mathrm{~s}^{-1}$, whereas the maximum cloud-mean-vertical velocity was $5.5 \mathrm{~m} \mathrm{~s}^{-1}$. The average and maximum LWC decreased as the PCASP concentration increased, with a median value of $0.078 \mathrm{~g} \mathrm{~m}^{-3}$ for $\mathrm{N}_{\text {PCASP }}<740 \mathrm{~cm}^{-3}$, and $0.056 \mathrm{~g} \mathrm{~m}^{-3}$ for $\mathrm{N}_{\text {PCASP }}>740 \mathrm{~cm}^{-3}$. The distribution of $r_{e}$ showed a positive skew with a median value of 9.22 microns for $N_{\text {PCASP }}<740$ $\mathrm{cm}^{-3}$ and 8.63 microns for $\mathrm{N}_{\text {PCASP }}>740 \mathrm{~cm}^{-3}$. We are currently summarizing the results of these studies for a publication that will be submitted in the near future.

\section{Publications and Conference Proceedings}

McFarquhar, G.M., J. Um, K. Bae, M. Freer, H. Jonsson, A. Korolev, R> Jackson, M. Poellot, J.W. Strapp, H.-.J. Yang, and G. Zhang, 2010: Integrated database of cloud microphysical properties from in-situ observations obtained during M-PACE, TWP-ICE, ISDAC and RACORO, First Atmospheric System Research Science Team Meeting, Bethesda, MD.

Yang, H.-J., G. McFarquhar, and H. Jonsson, 2011: Effect of aerosols on shallow cumuli sampled during RACORO. $2^{\text {nd }}$ Science Team Meeting of Atmospheric Systems Research Program, San Antonio, TX

Vogelmann, A.M., G. McFarquhar, J. Ogren, D. Turner, J. Comstock, G. Feingold, C. Long, H. Jonsson, A. Bucholtz, D. Collins, G. Diskin, H. Gerber, P. Lawson, R. K. Woods, E. Andrews, H.-J. Yang, J.C. Chiu, D. Harstock, J. Hubbe, C. Lo, A. Marshak, J.W. Monroe, S.A. McFarlane, B. Schmid, J.M. Tomlinson, and T. Toto, 2012: RACORO extended-term, aircraft observations of boundary layer clouds. Bull. Amer. Meteor. Soc., 93, 861-878.

McFarquhar, G.M., H.-J. Yang, and H. Jonsson, 2011: Controls on the microphysical properties of shallow cumuli sampled during RACORO. Atmospheric Systems Research Cloud Lifetime Working Group Fall Meeting, 12 to 16 September 2011, Annapolis, MD

Yang, H.-J., and G.M. McFarquhar, 2012: Effects of aerosols on shallow cumuli sampled during RACORO. $16^{\text {th }}$ Int. Conf. Clouds Precip., Leipzig, Germany, 28 July to 3 August 2012, Accepted for oral presentation.

Vogelmann, A., T. Toto, W. Lin, Y. Liu, C. Lu, M. Jensen, G. McFarquhar, R. Jackson, and H. Jonsson, 2012: RACORO Aircraft data case study development for FASTER. Pan-GCSS Meeting, Boulder, CO, September 2012.

Vogelmann, A., T. Toto, W. Lin, Y. Liu, C. Lu, M. Jensen, G. McFarquhar, R. Jackson, and H. Jonsson, 2012: RACORO Aircraft data case study development for FASTER. Pan-GCSS Meeting, Boulder, CO, September 2012. 
Vogelmann, A.M., T. Toto, W. Lin, Y. Liu, M.P. Jensen, C. Lu, G.M. McFarquhar, R. Jackson and H. Jonsson, 2012: RACORO aircraft data case study development for FASTER. Amer. Geophys. Union Fall Meeting, December 2012. 